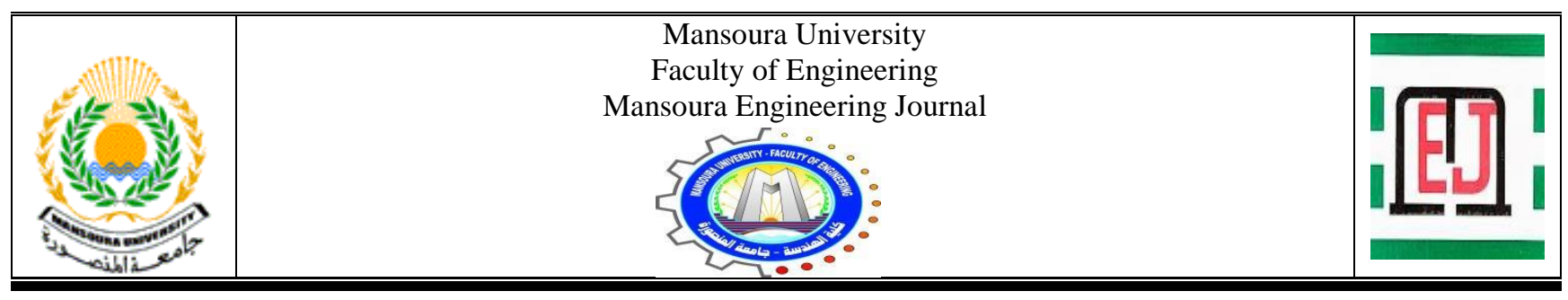

\title{
Laboratory Evaluation of Rice Husk and Sawdust on the Performance of Asphalt Binders and Mixtures
}

\author{
Manar M. Nassef, Alaa R. Gabr and Sherif M. El-Badawy
}

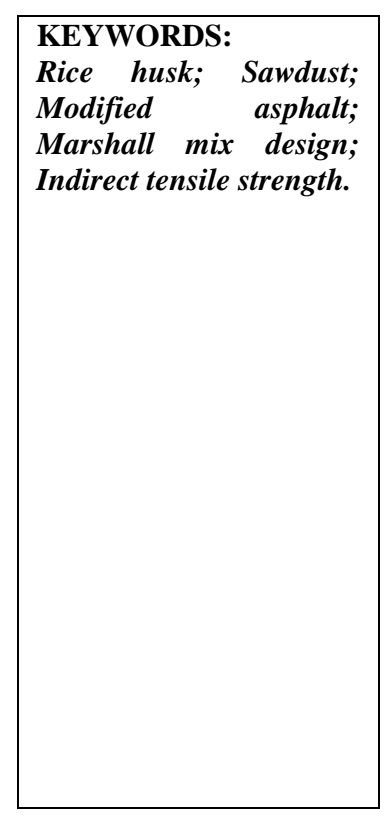

\begin{abstract}
Although waste materials have negative effects on the environment, they can be utilized in civil engineering applications, particularly in pavement construction. This research investigates the feasibility of using agricultural waste and byproduct materials i.e., Rice Husk (RH) and Sawdust (SD) as modifiers to asphalt binders and mixtures. A mechanical mixer was used at $1400 \mathrm{rpm}$ speed, and temperature of $140^{\circ} \mathrm{C} \pm 5^{\circ} \mathrm{C}$ to blend the byproduct material with a typical $60 / 70$ penetration grade asphalt for 60 minutes. Three different contents of 10,15 , and $20 \%$ by total weight of asphalt binder) were employed for modifying asphalt binders. Scanning Electron Microscopy (SEM) and, Fourier Transform Infrared Spectroscopy (FTIR) were used for the microstructural and chemical characterization of the modified asphalts. The neat and modified asphalts were tested against conventional properties. Modified asphalt mixtures were prepared and designed by Marshall method utilizing an optimum content of $15 \%$ by the total weight of asphalt binder for each of the byproduct materials. The moisture sensitivity was characterized in the laboratory for the control and modified mixes using the Tensile Strength Ratio (TSR) and loss of stability. Results showed that with the increase in the content of the waste/byproduct material, penetration value decreased, softening point temperature increased, and viscosity increased. Marshall stability of the prepared hot asphalt mixture containing RH-modified asphalt binder was the highest but with higher loss of stability compared with other asphalt mixes. The TSR of the control mix was the highest compared with other mixes.
\end{abstract}

Received: (26 August, 2021) - Revised: (12 October, 2021) - Accepted: (17 October, 2021)

Corresponding Author: Manar M. Nassef, Demonstrator at Delta Higher Institute for Engineering and Technology-MSc student, at Public Works Engineering Dept. Faculty of Engineering, Mansoura University.(E-mail: manar.nassef2@gmail.com).

Alaa R. Gabr, Associate Professor, Public Works Engineering Department, Faculty of Engineering, Mansoura University, Egypt. (E-mail: eng-alaa1400@mans.edu).

Sherif M. El-Badawy, Professor, Public Works Engineering Department, Faculty of Engineering, Mansoura University, Egypt. (E-mail: sbadawy@mans.edu.eg).

\section{INTRODUCTION}

$\mathrm{T}$ THERE is an increasing interest in the utilization of recycled and byproduct materials as alternative eco-materials in the civil engineering applications, especially in the pavement construction sector. Example of these eco-materials are reclaimed asphalt pavement, recycled concrete aggregate, demolition waste, marble dust, cement dust, crumb rubber, plastic waste, steel slag, waste oils, and others [1-14]. There are many benefits of using such materials in which they minimize the utilization of raw materials, reserve landfills, and sustainability. However, there still are some obstructions for adopting these materials in road construction. These obstructions are legalization, lack of clients' confidence in using these materials, and lack of 
performance-based specifications $[1,7]$.

Arabani and Tahami [15] evaluated the influence of Rice Husk Ash (RHA) with proportions of 5, 10, 15 and 20\% of total weight of asphalt on Hot Mix Asphalt (HMA) properties. Results showed an increase in softening point temperature, and viscosity, and a decrease in penetration with the addition of RHA to the asphalt. RHA modification to asphalt binder had positive effect on Marshall stability, stiffness modulus, rutting, and fatigue resistances of asphalt mixes.

Al-Hdabi [16] employed RHA instead of traditional mineral filler (ordinary Portland cement) in HMA. Results showed an improvement in the mechanical properties as well as durability of the modified asphalt mixtures in comparison with the control mixture.

Banerjee et al. [17] used RHA in HMA once as a mineral filler (stone dust) and then as a modifier to asphalt binder. They utilized RHA in HMA as a mineral filler by partial replacement of traditional filler $(1,2,3$, and $4 \%)$. While it was utilized to modify an $80 / 100$ asphalt by three different proportions $(10,20$, and 30\%) of the total asphalt binder weight. They found that using 10\% RHA modified asphalt in HMA produced higher stability values in comparison with the conventional mix. Finally, the use of RHA up to $3 \%$ as a filler exhibited similar stability values.

Mistry et al. [18] studied the effect of using two different waste materials, Fly Ash (FA) and RHA, as a replacement to the utilized filler, Hydrated Lime, HL, in HMA. Specimens of Dense graded Bituminous Macadam (DBM) mix were prepared with different proportions ranging between 2 and $8 \%$ of HL, RHA, and FA and designed according to Marshall method. Results showed better performance of DBM prepared with the increase in RHA, and FA contents compared with those prepared with the addition of HL.

Xue et al. [19] investigated two kinds of biomass ashes, RHA, and Wood Sawdust Ash (WSA) for the modification of asphalt binder. Fourier Transform Infrared Spectroscopy (FTIR) was utilized to characterize the impact of these materials on the chemical properties of asphalt. Results exhibited that there is no evidence of chemical reaction between biomass ashes and asphalt. With the increase of the RHA and WSA content, the viscosity at $135^{\circ} \mathrm{C}$ was increased. The rutting parameter of modified asphalt binders increased with the increase in RHA and WSA contents.

In another study by Abbasalizadeh and Hesami [20], asphalt mixture performance containing both fillers with different replacements to the limestone conventional filler was evaluated. Resilient modulus, stability, Indirect Tensile Strength (IDT), moisture sensitivity, and X-ray diffraction tests were utilized. The results showed that the blend of $25 \%$ limestone filler and 75\% RHA in HMA exhibited greater stability and improved moisture sensitivity in comparison with the HMA containing 100\% limestone filler. Furthermore, the blend of $75 \%$ limestone filler and 25\% WSA showed the best tensile performance.

Helal et al. [21] evaluated the effect of using RHA in HMA as a replacement of the Limestone Dust (LSD) filler. Five different HMA mixtures were prepared with different replacements of LSD of 0, 25, 50, 75, and 100\%. Marshall and IDT tests were performed as well as Dynamic modulus $\left(\left|E^{*}\right|\right)$ test. Results showed that the optimum replacement ratio was 50\%/50\% LSD/RHA, respectively. Generally, mixtures containing RHA enhanced Marshall Stiffness, IDT values, and dynamic modulus values.

Abdelmagid and Pei Feng [22] evaluated the use of Crumb Rubber Powder (CRP), RHA, and combination of CRP and RHA (CRP/RHA) as asphalt binder modifier. Different percentages of CRP $(5,10$, and $15 \%)$, and RHA (1, 4, and 7\%) by the total weight of asphalt binder were employed. The results showed an increase in softening point, penetration index, viscosity, complex modulus, and rutting parameter.

Akter and Hossain [23] investigated the influence of using RHA and slag in HMA as a filler compared with a stone dust conventional filler. Results showed that maximum stability was noted for HMAs containing RHA followed by stone dust and slag.

Over the last decades, due to the increase in population and urbanization, large quantities of waste and by-product materials are produced. These materials have become an enormous problem, since some of the materials are hazardous to be disposed in landfills, which affect plant life, and human health. Therefore, there a must to have some effective ways to utilize these waste and byproduct materials. Therefore, researcher over the last few decades started looking into the feasibility of using such materials in pavement applications.

The presented literature review showed an improved pavement performance using these waste/byproduct materials. However, the local properties of these materials and the binder properties affect the performance of the mixes modified with the waste/byproduct materials. In this research, an attempt is made to utilize two different agriculture waste/byproduct materials, which are Rice Husk (RH), and Sawdust (SD) as an asphalt binder and HMA modifier.

The properties of neat and modified asphalt binders with $\mathrm{RH}$ and SD as well as HMAs containing agricultural waste/byproducts, RH and SD were evaluated and compared with neat asphalt binder and conventional HMA.

\section{Materials AND MethodS}

\section{A. Materials}

Two different waste/byproduct materials were used in this study, which is RH and SD as a modifier to a typical asphalt binder and mixture. RH is one of the agricultural byproducts that widely available in the Delta region in Egypt. SD is a waste/byproduct of cutting, grinding, drilling, or pulverizing wood with a saw, which composed of fine particles of wood. Only the fine particles that passed the $150 \mu \mathrm{m}$ sieve (US standard Sieve No. 100) of the investigated materials were collected to be utilized in this study as a modifier. Conventional coarse aggregate \#1 and \#2, crushed sand, and HL powder (filler) were used for the preparation of HMAs. A typical 60/70 penetration grade neat asphalt binder was used. 
The asphalt binder was sourced from Alexandria Company, Egypt.

\section{B. Experimental Work}

The experimental program was categorized to three major tasks: i) determination of the mixing process of the waste/byproduct materials with asphalt binder, ii) characterization of the neat and modified asphalt binders, and iii) design of asphalt mixtures containing neat and modified asphalt binders by Marshall method and moisture sensitivity evaluation. Figure 1 outlines the flow chart of the experimental work program.

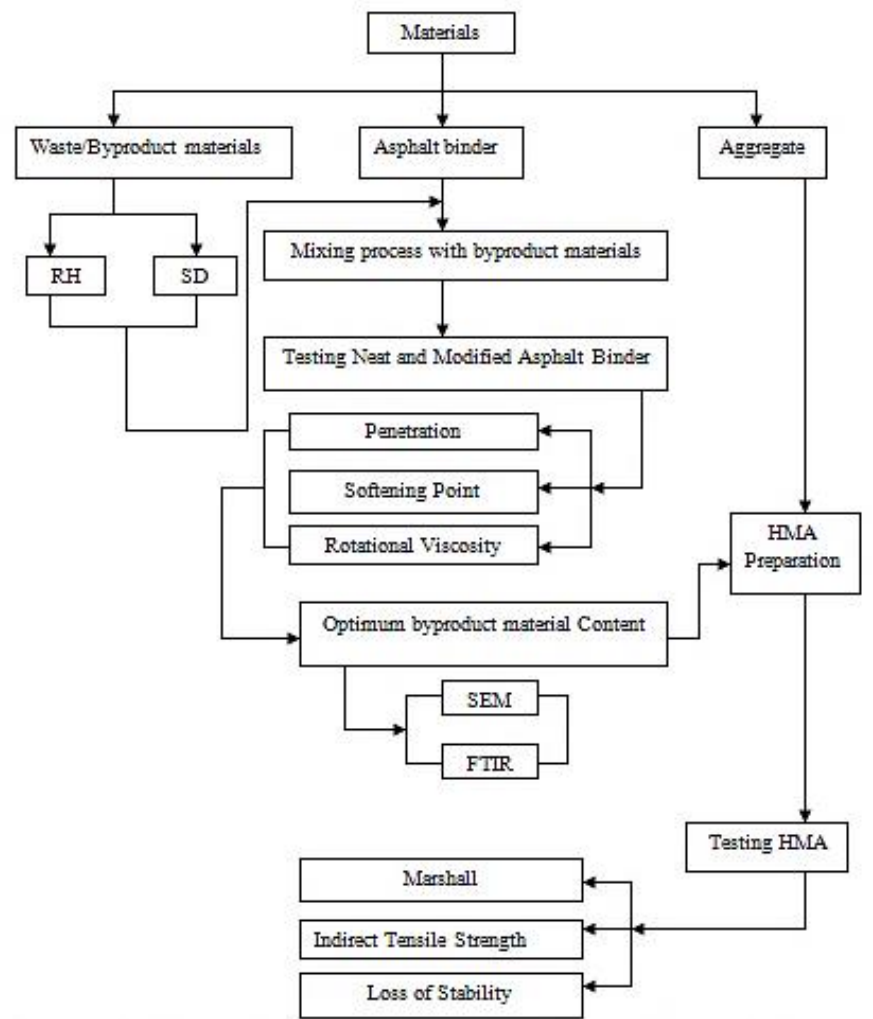

RH: Rice husk; SD: Sawdust; SEM: Scanning electron microscopy; FTIR: Fourier Transform Infrared Spectroscopy

Fig. 1 Experimental Work Outline

A detailed description of the experimental program tasks is as follows:

To ensure the homogeneity of the mix of asphalt and waste/byproduct material, a mechanical mixer was used with a $1400 \mathrm{rpm}$ speed. The suitable mixing time was investigated by the Brookfield Rotational Viscometer (RV) test by mixing a $15 \%$ of the investigated $\mathrm{RH}$ with the asphalt binder at a mixing temperature of $140^{\circ} \mathrm{C} \pm 5^{\circ} \mathrm{C}$. Table 1 shows slightly better viscosity values for asphalt binder modified with $15 \%$ $\mathrm{RH}$ at mixing times of 30 and 60 minutes, respectively. Thus, a mixing time of 60 minutes was chosen for mixing the byproduct materials with the asphalt binder.
TABLE 1

ROTATIONAL VISCOSITY OF THE RH MODIFIED ASPHALT BINDER AT DIFFERENT MIXING TIMES AND TEMPERATURES

\begin{tabular}{l||l||l}
$\begin{array}{c}\text { Temperature } \\
\left({ }^{\circ} \mathbf{C}\right)\end{array}$ & \multicolumn{1}{|c||}{$\begin{array}{c}\text { Viscosity }(\mathbf{c P}) \text { for } \mathbf{3 0} \\
\text { minutes }\end{array}$} & $\begin{array}{c}\text { Viscosity }(\mathbf{c P}) \text { for } \mathbf{6 0} \\
\text { minutes }\end{array}$ \\
\hline 135 & 786.70 & 828.35 \\
\hline 150 & 381.50 & 407.45 \\
\hline 165 & 218.80 & 229.0
\end{tabular}

For testing the asphalt binders, a control specimen, referred to as $0 \%$ byproduct material, was firstly tested before adding modifiers. Specimens of the neat asphalt were then mixed with contents of 10,15 , and $20 \%$ of RH and SD by the total weight of the asphalt at a temperature of $140^{\circ} \mathrm{C} \pm 5^{\circ} \mathrm{C}$ for one hour. Penetration, softening point temperature, and RV tests were performed on the control and modified asphalt binder at the Highway and Airport Engineering Laboratory (HAEL), Mansoura University. In addition, Scanning Electron Microscopy (SEM), and FTIR tests were conducted on the modified asphalt binders by 15\% RH and 15\% SD at Faculty of Agriculture, and Faculty of Science, Mansoura University.SEM specimens of the modified asphalt binders were placed on a test beam in a vacuum chamber and the asphalt binder was coated with gold as electrically conducting metal, then scanned under the electron microscope. FTIR specimens of the asphalt binders were analyzed utilizing a Thermo Fisher Nicolet IS10 located at Faculty of Science, Mansoura University.

For designing asphalt mixtures by Marshall method, aggregates were blended to achieve the target gradation as specified by the Egyptian Code of Practice (ECP) [24] for 4-C wearing surface as presented in Figure 2. The job mix formula of the control mix is $12,28,55$, and $5 \%$, of aggregate \#1, aggregate $\# 2$, sand, and mineral filler, respectively by the total weight of the mix. The control and modified asphalt mixtures containing $15 \% \mathrm{RH}$ and $15 \%$ SD by the total weight of the asphalt binder were designed according to Marshall method AASHTO T 245 [25]. Marshall Stability and flow for each asphalt mixture were determined for the prepared specimens after placing them in a $60^{\circ} \mathrm{C}$ water bath for 30 minutes.

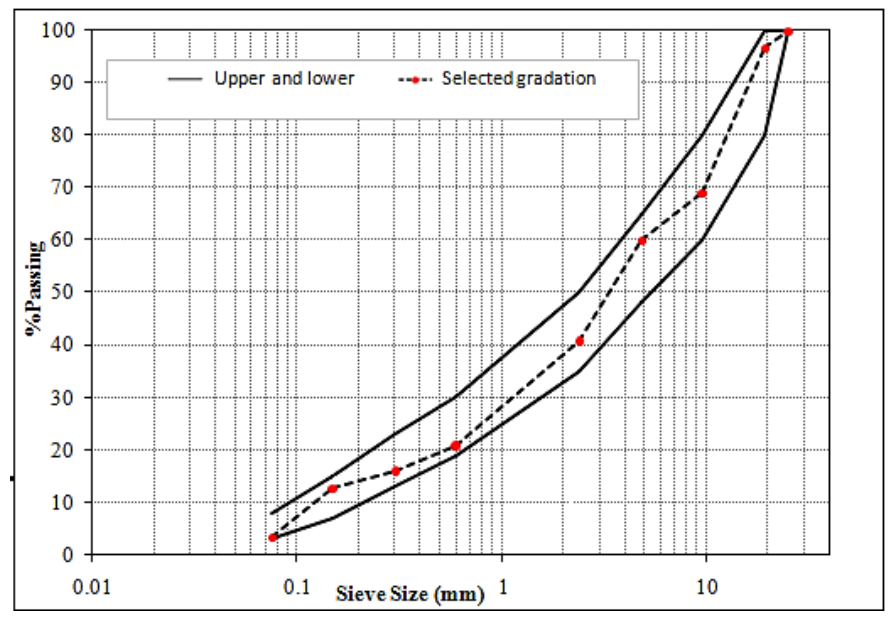

Fig. 2 Design aggregate gradation and specification limits for 4-C wearing asphalt course 
The loss of stability test was conducted according to ASTM D1559 [26]. For each asphalt mixture, two sets of specimens were compacted in Marshall compactor, then one set of specimens was conditioned in a $60^{\circ} \mathrm{C}$ water bath for 24 hrs (conditioned specimens). Loss of Stability was calculated as described in the following equation:

Loss of stability (\%)

$$
=1-\frac{\text { Stability of conditioned samples }}{\text { Stability of unconditioned samples }}
$$

For the IDT test, six HMA specimens (three unconditioned, dry, and three conditioned, wet) were prepared at $7 \%$ air voids for each asphalt mixture. The wet specimens were exposed to vacuum saturation to achieve $55-80 \%$ water saturation, then placed in a water bath of $60^{\circ} \mathrm{C}$ for $24 \mathrm{hrs}$ according to ASTM D4867 [27], then placed in water bath at $25^{\circ} \mathrm{C}$ for 1 hour and tested.

\section{RESULTS AND DISCUSSION}

Figures 3 and 4 shows the influence of the byproduct material type, and proportion on penetration and softening point temperature of the asphalt binders. Figure 3 shows the relationship between the byproduct materials (RH and SD) percentage and penetration $(0.1 \mathrm{~mm})$.It can be seen from Figure 3 that a decrease in the penetration value was noted with the increase in the content of both $\mathrm{RH}$ and SD. The penetration values were 71.6, 60.3, 59.3 and 52.7 for $0,10,15$, and $20 \% \mathrm{RH}$, while they were lower (harder blends) for SD with values of 71.6, 53.3, 46.7, and 45 at the same contents.

The softening point temperatures, shown in Figure 4, increased with the modification of neat asphalt binder by both $\mathrm{RH}$ and SD. The addition of RH increased the softening point from $38^{\circ} \mathrm{C}$ (control specimen) to $45.9^{\circ} \mathrm{C}$ at $20 \%$, however for $\mathrm{SD}$ it was increased to $51.3^{\circ} \mathrm{C}$ at $20 \%$. The minimum softening point temperature required by the $\mathrm{ECP}$ is $45^{\circ} \mathrm{C}$ [24].

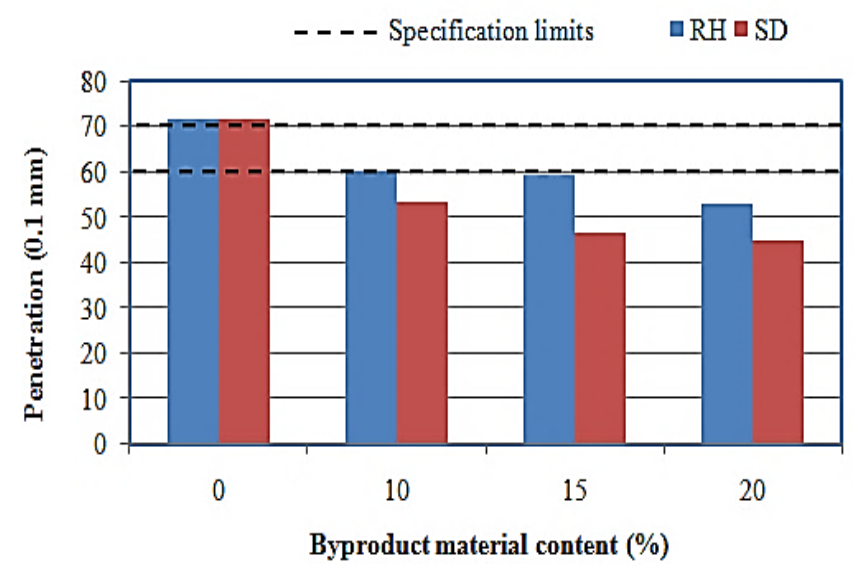

Fig. 3 Effect of the Waste/Byproduct Material Content on Asphalt Binder Penetration

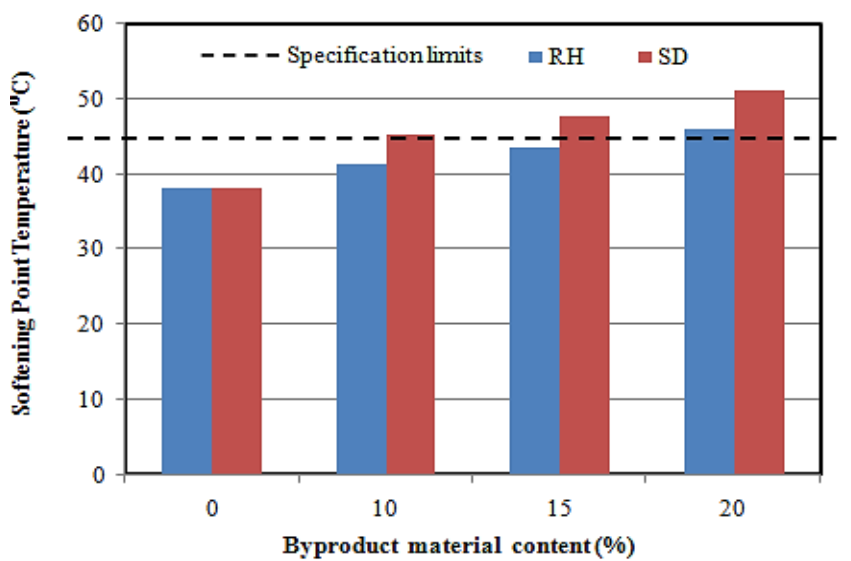

Fig. 4 Effect of the Waste/Byproduct Material Content on sphalt Binder Softening Point Temperature

Figure 5 shows the impact of the waste/byproduct material content on the asphalt viscosity at different elevated temperatures. It is noticeable that a significant increase in the viscosity occurred with using byproduct materials at all levels of temperatures in particular for the SD additive. As the temperature increases, the viscosity reduces gradually. Based on the results of penetration, softening point and RV tests presented in Figures 3 to 5, the appropriate content of byproduct material as an asphalt modifier was selected as $15 \%$ of each of the byproduct materials.

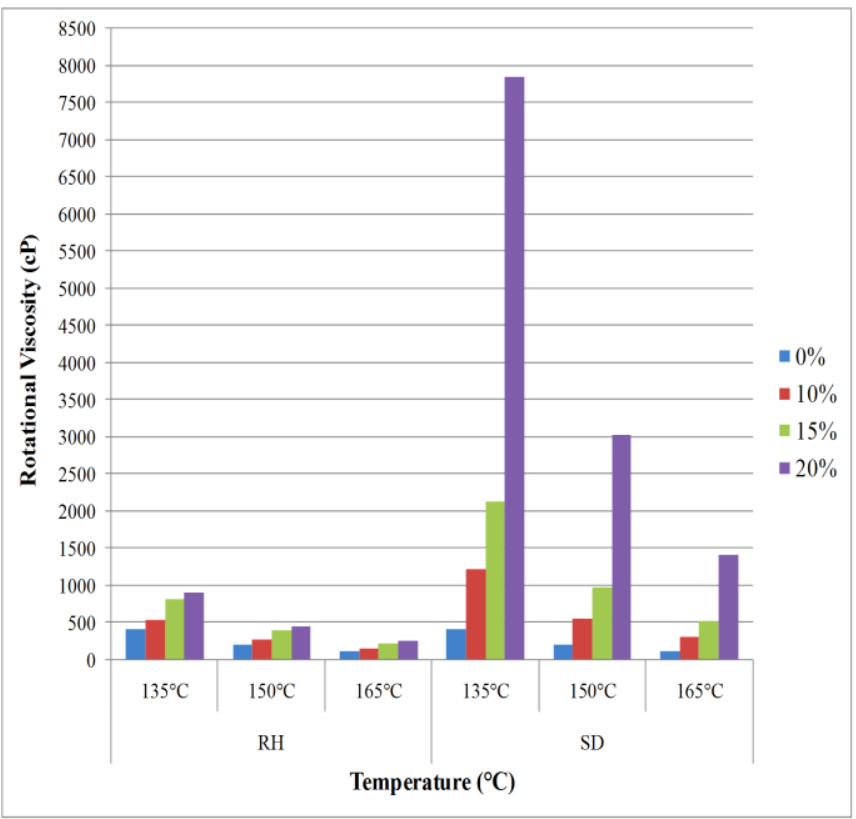

Fig. 5 Effect of Byproduct Material Content on Rotational Viscosity at Different Temperatures

Figure 6 presents the ASTM Ai-VTSi relationships according to the ASTM D4402 [28] for the neat and modified asphalt binders along with the coefficient of determination (R2). There was a decrease in the viscosity-temperature susceptibility (Ai-VTSi) values for RH and SD compared with 
the neat asphalt binder, meaning better performance at lower and higher temperatures.

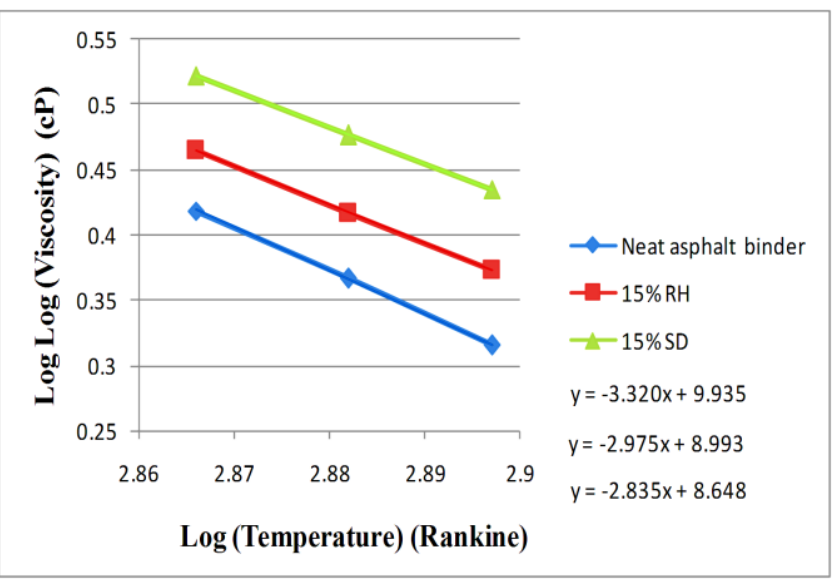

Fig. 6 Ai-VTSi Relationships for Neat and Modified Asphalt Binders

Figure 7 shows the SEM images of the different asphalt binder specimens for each modifier type. A good dispersion can be observed for the RH modified asphalt binder, while there was some agglomeration for the SD modified asphalt compared with the RH modified asphalt.

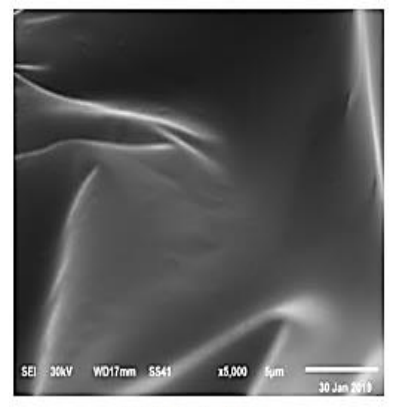

(a) Neat Asphalt

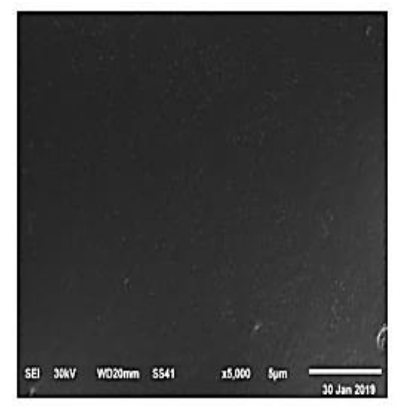

(b) Asphalt Modified with RH

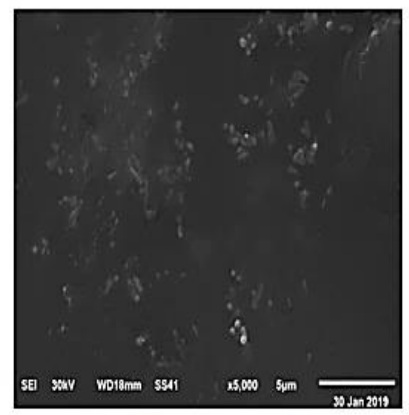

(c) Asphalt Modified with SD

Fig. 7 SEM Images for Neat and Modified Asphalt Binders

The FTIR technique was utilized to determine the surface function groups of the dye adsorbent. Figure 8 shows the FTIR spectrum of the neat and modified asphalt binders.

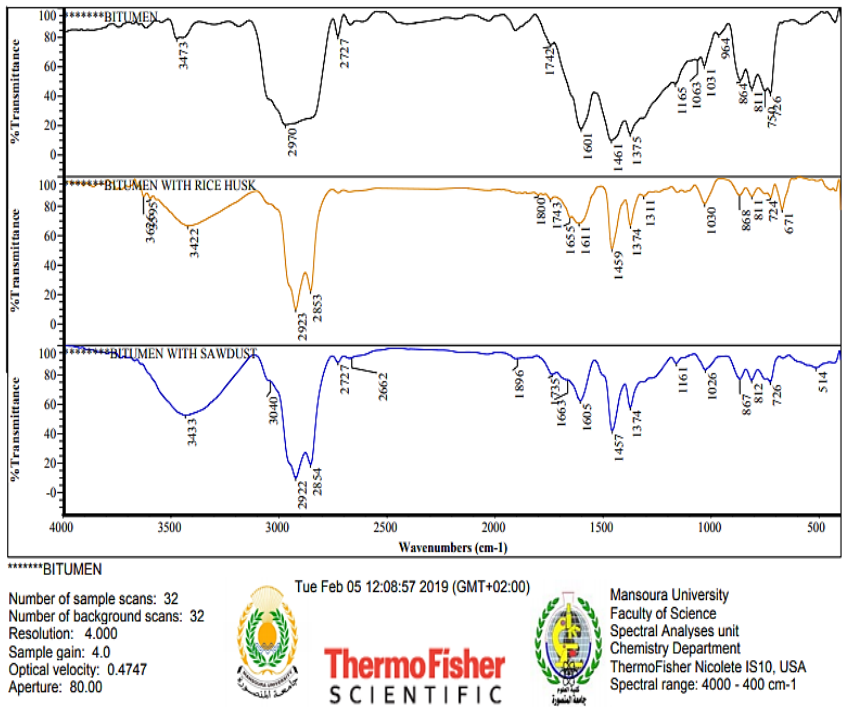

Fig. 8 FTIR Spectrum for Neat and Modified Asphalt Binders

The FTIR spectrum of the neat asphalt shows absorption band at $2970 \mathrm{~cm}^{-1}$ due to the presence of $\mathrm{CH}$ aliphatic. It also depicts absorption bands at $1601 \mathrm{~cm}^{-1}$, and $1165 \mathrm{~cm}^{-1}$ owing to the presence of $\mathrm{C}=\mathrm{C}$, and $\mathrm{C}-\mathrm{O}$ function groups in neat asphalt, respectively.

The FTIR spectrum of both RH and SD modified asphalt binders show the presence of $\mathrm{OH}$ broad at absorption bands at $3422 \mathrm{~cm}^{-1}$ and $3433 \mathrm{~cm}^{-1}$, respectively. Two other absorption bands were noted at $2923 \mathrm{~cm}^{-1}$ and $2854 \mathrm{~cm}^{-1}$ for both RH and SD modified binders due to the existence of $\mathrm{CH}$ aliphatic.

Table 2 summarizes the Marshall stability and flow as well as the volumetric properties of investigated asphalt mixes. The Optimum Asphalt Content (OAC) of the control mix was found to be $5.37 \%$. while it was $4.57 \%$ and $5.20 \%$ for the RH and SD asphalt mixtures, respectively. The Marshall stability for all mixes achieved the Egyptian specifications, which require $900 \mathrm{~kg}$ as a minimum value [24]. It can be noted that Marshall stability of the prepared HMA mixture using RHmodified binder was the highest stability despite the relatively lower Voids in Mineral Aggregate (VMA). Although, the higher viscosity of the SD modified asphalt and the higher VMA, the HMA containing 15\% SD yielded the lowest stability due to the lower density compared with those of other mixes. The existence of SD in HMA increased relatively the Voids Filled with Asphalt (VFA) yielding lower durable mix compared with those of other mixes. 
TABLE 2

MARSHALL PROPERTIES FOR THE INVESTIGATED ASPHALT MIXES

\begin{tabular}{|c|c|c|c|c|}
\hline Mix Property & $\begin{array}{c}\text { Contro } \\
1\end{array}$ & $15 \%$ RH & $\begin{array}{l}15 \% \\
\text { SD }\end{array}$ & $\begin{array}{c}\text { ECP Specification } \\
\text { limits }\end{array}$ \\
\hline $\begin{array}{l}\text { Asphalt Content } \\
\text { by Weight }(\%)\end{array}$ & 5.37 & 4.57 & 5.20 & $4-7.5$ \\
\hline $\begin{array}{l}\text { Marshall } \\
\text { Stability }(k g)\end{array}$ & $\begin{array}{l}1365.6 \\
2\end{array}$ & 1569.14 & $\begin{array}{l}1212.9 \\
0\end{array}$ & 900 minimum \\
\hline $\begin{array}{l}\text { Marshall Flow } \\
(\mathrm{mm})\end{array}$ & 3.74 & 3.56 & 3.71 & $2-4$ \\
\hline $\begin{array}{l}\text { Bulk Specific } \\
\text { Gravity, Gmb }\end{array}$ & 2.318 & 2.280 & 2.221 & - \\
\hline $\begin{array}{l}\text { Theoretical } \\
\text { Maximum } \\
\text { Specific Gravity, } \\
\text { Gmm }\end{array}$ & 2.384 & 2.344 & 2.332 & - \\
\hline Air Voids (\%) & 3.0 & 3.0 & 4.7 & $3-5$ \\
\hline $\begin{array}{l}\text { Voids in Mineral } \\
\text { Aggregate, VMA }\end{array}$ & 14.4 & 12.6 & 15.6 & $12-14$ minimum \\
\hline $\begin{array}{l}\text { Voids Filled } \\
\text { with Asphalt, } \\
\text { VFA }\end{array}$ & 80.9 & 78.2 & 69.5 & - \\
\hline $\begin{array}{l}\text { Effective binder } \\
\text { content by } \\
\text { weight (\%) }\end{array}$ & 5.10 & 4.37 & 4.94 & \\
\hline
\end{tabular}

Figure 9 depicts the loss of stability results for the three asphalt mixtures. Although the RH and SD asphalt mixtures yielded higher loss of stability compared to the control mix, it was lower than the maximum limit of $25 \%$ according to the ECP [24].

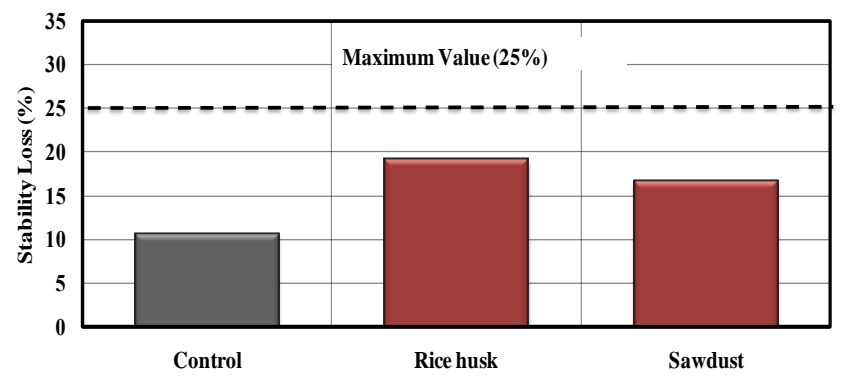

Fig. 9 Loss of stability values for the Control and Modified HMA

Figure 10 shows the Tensile Strength Ratio (TSR) results for the investigated mixes. Generally, the different mixes achieved the minimum requirement of TSR value of $80 \%$ as specified by [24]. It is evident from the figure that the control HMA mixture yielded higher TSR in comparison with the modified HMA mixtures.

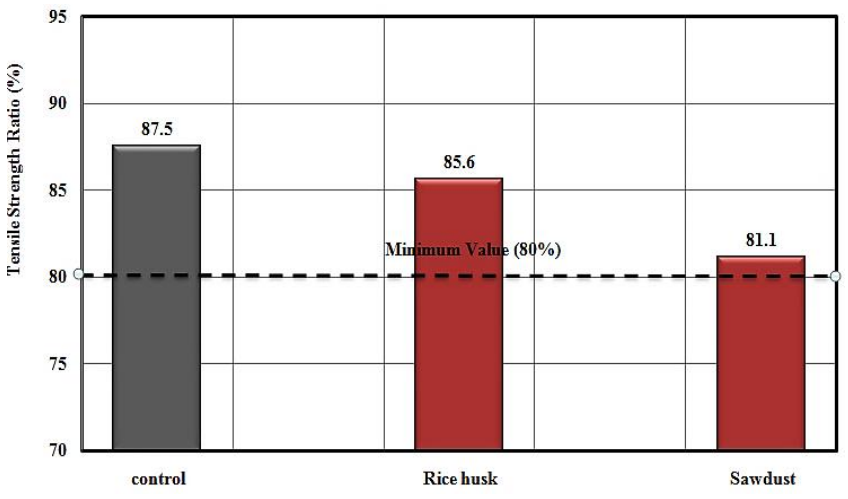

Fig. 10 Tensile Strength Ratio for the investigated Asphalt Mixtures

\section{Conclusion}

This study focused on using agriculture waste/byproduct materials (RH and SD) to modify a typical 60/70 penetration grade neat asphalt binder. Modified asphalt mixtures by $15 \%$ RH and 15\% SD were designed by Marshall method and their properties were evaluated and compared with a control mix. Based on the results and analyses of this study, the following conclusions can be drawn:

- Mixing time of 60 minutes at a $1400 \mathrm{rpm}$ speed and a mixing temperature of $140^{\circ} \mathrm{C} \pm 5^{\circ} \mathrm{C}$ was observed enough to achieve good dispersion of the investigated waste/byproduct materials, as evidenced by SEM images and $\mathrm{RV}$ results.

- By the addition of either RH or SD into asphalt binder, both of softening point temperature and viscosity increased, and penetration decreased yielding better blend for hotter climates and/or heavier traffic loading.

- Based on the results of penetration, softening point, and viscosity results, the appropriate content of the investigated agriculture waste/byproduct materials was $15 \%$.

- HMA mixtures prepared by $15 \%$ RH yielded the highest stability values followed by the control, and SD HMA mixtures. The lowest stability was for HMA containing SD due to the lowest density and highest VMA and air voids in comparison with other mixes.

- All investigated mixtures showed good resistance to moisture damage in terms of the loss of stability and the TSR. However, adding the RH or SD slightly affected the moisture resistance of the mix compared to the neat binder.

\section{Authors CONTRIBUTION}

Contributions of authors to the paper are outlined as follow:

1. Conception or design of the work: Sherif El-Badawy

2. Data collection and tools: Manar M. Nassef 
3. Data analysis and interpretation: Manar M. Nassef and Alaa R. Gabr

4. Methodology: Alaa R. Gabr, and Sherif M. El-Badawy

5. Supervision: Alaa R. Gabr, and Sherif M. El-Badawy

6. Drafting the article: Manar M. Nassef, and Alaa R. Gabr

7. Critical revision of the article: Alaa $\mathbf{R}$. Gabr

8. Final approval of the version to be published: Alaa $\boldsymbol{R}$. Gabr, and Sherif M. El-Badawy

\section{FUNDING STATEMENT:}

The author did not receive any financial support of the research authorship and publication of this article

\section{DECLARATION OF CONFLICTING INTERESTS STATEMENT:}

The author declared that there are no potential conflicts of interest with respect to the research authorship or publication of this article

\section{REFERENCES}

[1] S. M. El-Badawy, A. R. Gabr, and R. T. Abd El-Hakim, "Recycled materials and by-products for pavement construction," Handb. Ecomater. Springer, New York, pp. 1-22, 2018.

[2] D. El-Tahan, A. Gabr, S. El-Badawy, and M. Shetawy, "Evaluation of recycled concrete aggregate in asphalt mixes," Innov. Infrastruct. Solut., 3(1), pp. 1-13, 2018.

[3] E. Mousa, S. El-Badawy, and A. Azam, "Effect of reclaimed asphalt pavement in granular base layers on predicted pavement performance in Egypt,” Innov. Infrastruct. Solut., vol. 5, pp. 1-18, 2020.

[4] M. Shiha, S. El-Badawy, and A. Gabr, "Modeling and performance evaluation of asphalt mixtures and aggregate bases containing steel slag," Constr. Build. Mater., vol. 248, p. 118710, 2020.

[5] A. M. El-Shorbagy, S. M. El-Badawy, and A. R. Gabr, "Investigation of waste oils as rejuvenators of aged bitumen for sustainable pavement," Constr. Build. Mater., vol. 220, pp. 228-237, 2019.

[6] E. W. Tarbay, A. M. Azam, and S. M. El-Badawy, "Waste materials and by-products as mineral fillers in asphalt mixtures," Innov. Infrastruct. Solut., 4(1), pp. 1-13, 2019.

[7] A. Gabr, D. Cameron, R. Andrews, and P. Mitchell, "Comparison of specifications for recycled concrete aggregate for pavement construction," Journal of ASTM International,8(10), 15 pp., DOI: 10.1520/JAI103646, 2011.

[8] A. M. Arisha, A. R. Gabr, S. M. El-Badawy, and S. A. Shwally, "Performance evaluation of construction and demolition waste materials for pavement construction in Egypt," J. Mater. Civ. Eng., 30(2), p. 4017270, 2018.

[9] Y. Alghrafy, S. El-Badawy, and E.-S. M. AbdAlla, "A Comparative Study of Different Complex Shear Modulus Master Curve Techniques for Sulfur Extended Asphalt Modified with Recycled Polyethylene Waste," Int. J. Pavement Res. Technol., pp. 1-28, 2021.

[10] R. T. Abd El-Hakim, G. M. Elgendy, S. M. El-Badawy, and M. Amin, "Performance evaluation of steel slag high performance concrete for sustainable pavements," Int. J. Pavement Eng., pp. 1-19, 2021.

[11] Y. M. Alghrafy, E.-S. M. AbdAlla, and S. M. El-Badawy, "Rheological properties and aging performance of sulfur extended asphalt modified with recycled polyethylene waste," Constr. Build. Mater., vol. 273, p. 121771, 2021.

[12] A. M. Awed, A. E. Aboelela, A. S. El-Ashwah, M. Allam, and S. M. ElBadawy, "Improvement of unbound granular pavement layers and subgrade with cement dust in Egypt," Int. J. Pavement Res. Technol., 13(6), pp. 621-629, 2020.

[13] A. M. Awed, E. W. Tarbay, S. M. El-Badawy, and A. M. Azam, "Performance characteristics of asphalt mixtures with industrial waste/by-product materials as mineral fillers under static and cyclic loading," Road Mater. Pavement Des., pp. 1-23, 2020.

[14] E. Mousa, S. El-Badawy, and A. Azam, "Evaluation of reclaimed asphalt pavement as base/subbase material in Egypt," Transp. Geotech., vol. 26, p. 100414, 2021.
[15] M. Arabani and S. A. Tahami, "Assessment of mechanical properties of rice husk ash modified asphalt mixture," Constr. Build. Mater., vol. 149, pp. 350-358, 2017.

[16] A. Al-Hdabi, "Laboratory investigation on the properties of asphalt concrete mixture with Rice Husk Ash as filler," Constr. Build. Mater., vol. 126, pp. 544-551, 2016.

[17] J. Banerjee, J. A. Barbhuiya, and P. Rajbongshi, "The Effective Ways of Utilization of Rice-Husk-Ash in Hot Mix Asphalt," J. Basic Appl. Eng. Res., 3(4), pp. 309-314, 2016.

[18] R. Mistry, S. Karmakar, and T. Kumar Roy, "Experimental evaluation of rice husk ash and fly ash as alternative fillers in hot-mix asphalt," Road Mater. Pavement Des., 20(4), pp. 979-990, 2019.

[19] Y. Xue, S. Wu, J. Cai, M. Zhou, and J. Zha, "Effects of two biomass ashes on asphalt binder: Dynamic shear rheological characteristic analysis," Constr. Build. Mater., vol. 56, pp. 7-15, 2014.

[20] S. AbbasalizadehBoura and S. Hesami, "Laboratory evaluation of the performance of asphalt mixtures containing biomass fillers," Road Mater. Pavement Des., 21(7), pp. 2040-2053, 2020.

[21] M. M. E. Helal, H. A. Mahdy, and M. F. Ibrahim, "Effect of Rice Husk Ash on the Performance of Hot Asphalt Mixes," MEJ. Mansoura Eng. J., 45(2), pp. 8-19, 2020.

[22] A. A. A. Abdelmagid and C. Pei Feng, "Evaluating the effect of ricehusk ash and crumb-rubber powder on the high-temperature performance of asphalt binder," J. Mater. Civ. Eng., 31(12), p. 4019296, 2019.

[23] R. Akter and M. K. Hossain, "Influence of Rice Husk Ash and Slag as Fillers in Asphalt Concrete Mixes," Am. J. Eng. Res., 6(1), pp. 303-311, 2018.

[24] Egyptian Code for Urban and Rural Roads. Part 4. Road Material and its Tests: Housing and Building National Research Center, Egypt, 2008.

[25] AASHTO T245-15, Standard Test Method for Marshall Stability and Flow of Asphalt Mixtures. American Association of State and Highway Transportation Officials. Washington, DC, USA., 2015.

[26] ASTM D1559-89, Test Method for Resistance of Plastic Flow of Bituminous Mixtures Using Marshall Apparatus. ASTM International, West Conshohocken, PA, 1998.

[27] ASTM D4867, Standard practice for effect of moisture on asphalt concrete paving mixture. ASTM International, West Conshohocken, PA, 2009.

[28] ASTM D4402/D4402M, Standard Test Method for Viscosity Determination of Asphalt at Elevated Temperatures Using a Rotational Viscometer. ASTM International, West Conshohocken, PA, 2015.

\section{Title in Arabic:}

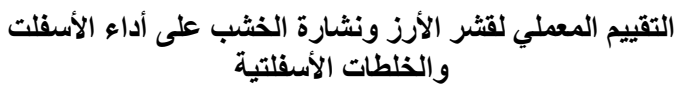

\section{Abstract in Arabic:}

على الرغم من أن المخلفات لها آثار سلبية على البيئة، إلا أنه يمكن استخدامها في

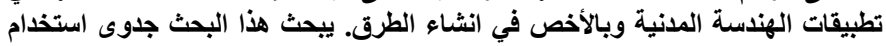

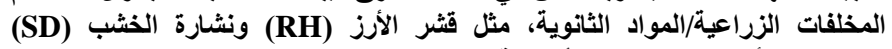

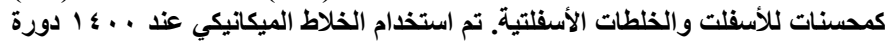

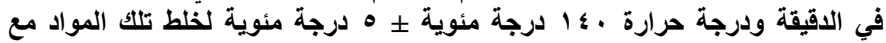

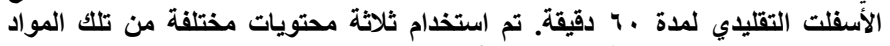

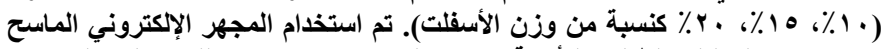
(SEM)

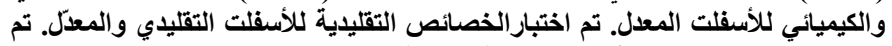

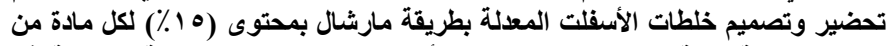

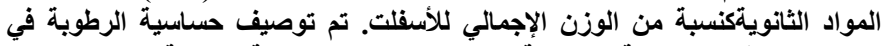

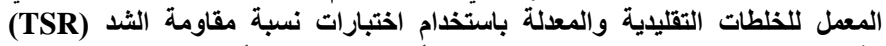

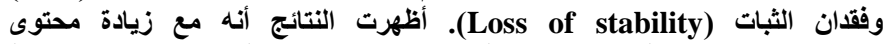

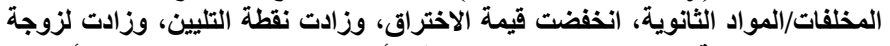

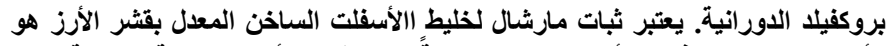

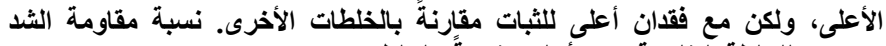
(TSR) 